\title{
Federal Research Funding for Family Medicine: Highly Concentrated, with Decreasing New Investigator Awards
}

\author{
Brianna J. Cameron, MPH, Andrew W. Bazemore, MD, MPH, \\ and Christopher P. Morley, PhD, MA
}

\begin{abstract}
A small proportion of National Institutes of Health and other federal research funding is received by university departments of family medicine, the largest primary care specialty. That limited funding is also concentrated, with roughly a quarter of all National Institutes of Health, Centers for Disease Control and Prevention, and Agency for Healthcare Research and Quality funding awarded to 3 departments, almost half of that funding coming from 3 agencies, and a recent trend away from funding for new investigators. (J Am Board Fam Med 2016;29:531-532.)
\end{abstract}

Keywords: Awards \& Prizes, Center for Disease Control \& Prevention (U.S.), Family Practice, Grants, Primary Health Care, Research

Previous reports have revealed that Family Medicine $(\mathrm{FM})$ as a specialty receives relatively little federal research funding, despite delivering a wide

This article was externally peer reviewed.

Submitted 19 February 2016; revised 16 May 2016; accepted 31 May 2016.

From Central New York Master of Public Health Alumnus, SUNY Upstate Medical University, Syracuse, NY (BJC); the Robert Graham Center for Policy Studies, Washington, DC (AWB); and the Departments of Family Medicine, Public Health \& Preventive Medicine, and Psychiatry \& Behavioral Sciences, SUNY Upstate Medical University, Syracuse (CPM).

Funding: This project was partially supported by the Health Resources and Services Administration of the U.S. Department of Health and Human Services under grant D54HP23297, “Academic Administrative Units," for roughly \$2000 (total award amount $\$ 154,765$; $90 \%$ financed with nongovernmental sources), corresponding to the amount of effort dedicated to this project by the lead author (BJC).

Conflict of interest: none declared.

Disclaimer: This information or content and conclusions are those of the authors and should not be construed as the official position or policy of, nor should any endorsements be inferred by, the Health Resources and Services Administration, the U.S. Department of Health and Human Services, or the U.S. government.

Corresponding author: Christopher P. Morley, PhD, MA, Department of Family Medicine, SUNY Upstate Medical University, 750 East Adams St, MIMC 200, Syracuse, NY 13066 (E-mail: morleycp@upstate.edu).

\section{See Related Commentary on page 525}

range of care to a diverse set of patients and populations. ${ }^{1-3}$ In addition, this limited funding has been shown to be concentrated to a small number of funders and recipient institutions, which can pose a barrier to building research capacity within less established departments of FM (DFMs) and the specialty as a whole. ${ }^{1}$

We used the National Institutes of Health (NIH) RePORTER tool ${ }^{4}$ to quantify the number of US Department of Health and Human Services grants, including from the NIH, the Agency for Healthcare Research and Quality, and the Centers for Disease Control and Prevention, that were awarded to DFMs over the study period of 2002 to 2014. We specifically sought to determine how NIH FM grants are classified by activity code, academic department, and funding institute or center. ${ }^{4}$

There seems to be an increasing concentration by department. From 2007 to 2014, 3 departments received one quarter of all grants awarded to DFMs by the NIH-an increase from one fifth during 2002 to 2006. Notably, all 3 of these departments combine FM and public health. Grants were also awarded by a limited number of institutes or funding agencies. Across the 13-year time frame of the study, the top 3 administering institutes or centers funded nearly half of all grants awarded to DFMs 
Table 1. National Institutes of Health Grants Awarded to Departments of Family Medicine from 2002 to 2014, Classified by Activity Code, Department of Family Medicine, and Administering Institute or Center

\begin{tabular}{|c|c|c|c|}
\hline & $2002-2006^{*}$ & $2007-2010$ & 2011-2014 \\
\hline \multicolumn{4}{|l|}{ By activity code } \\
\hline $\mathrm{R}$ & 67 & 59 & 59 \\
\hline $\mathrm{K}$ & 22 & 21 & 15 \\
\hline $\mathrm{U}$ & 7 & 12 & 16 \\
\hline Other & 4 & 8 & 10 \\
\hline \multicolumn{4}{|l|}{ By department of family medicine } \\
\hline $\begin{array}{l}\text { University of California, San } \\
\text { Diego }\end{array}$ & 8 & 14 & 13 \\
\hline Dartmouth College & 8 & 5 & 6 \\
\hline University of Minnesota & 4 & 4 & 5 \\
\hline Other & 80 & 76 & 76 \\
\hline \multicolumn{4}{|l|}{ By institute or center } \\
\hline NCI & 24 & 27 & 28 \\
\hline AHRQ & 14 & 8 & 11 \\
\hline NHLBI & 8 & 9 & 8 \\
\hline Other & 53 & 56 & 54 \\
\hline
\end{tabular}

Data are percentages. Percentages totals may not sum to $100 \%$ because of rounding error.

${ }^{*}$ Data from 2002 to 2006 are not consistent with the data from Lucan et al. ${ }^{1}$ because of different methods of data collection.

AHRQ, Agency for Healthcare Research and Quality; K, research career programs; NCI, National Cancer Institute; NHLBI, National Heart Lung and Blood Institute; R, research projects; U, cooperative agreements.

(Table 1). The primary administering agency for FM grants is the National Cancer Institute, which funded $28 \%$ of NIH grants for FM research over 2011 to 2014, followed by Agency for Healthcare Research and Quality (11\%) and the National Heart, Lung, and Blood Institute (8\%). In terms of award type, funding for research training awards (K-series) to DFMs has declined, from $22 \%$ over 2002 to 2006 to $15 \%$ from 2011 to 2014 .

An already thin stream of research funding from federal agencies also concentrates in a few universities, revealing that most funded DFMs depend on a small number of federal institutes and centers. There may be a number of endogenous factors within the specialty of FM that contribute to the issue, including fewer research fellowships or other training opportunities across the field, as well as a weaker overall research infrastructure in FM. It is also possible that applications for funding from institutions that do not have strong research support simply lack the necessary rigor. Regardless, there seems to be an opportunity to strengthen the primary care research enterprise through university efforts to grow DFM research capacity, increased attention to the importance of primary care research across the federal research community, and efforts to reverse the decline in $\mathrm{K}$-series awards being made to new investigators in DFMs.

\section{References}

1. Lucan SC, Phillips RL Jr, Bazemore AW, Phillips RL, Bazemore AW. Off the roadmap? Family medicine's grant funding and committee representation at NIH. Ann Fam Med 2008;6:534-42.

2. Morley CP, Bazemore AW, Cameron BJ. The impact of administrative academic units (AAU) grants on the family medicine research enterprise in the United States. Fam Med 2016;48:452-8.

3. Cameron BJ, Bazemore AW, Morley CP. Lost in translation: NIH funding for family medicine research remains limited. J Am Board Fam Med 2016; 29:528-30.

4. U.S. Department of Health \& Human Services. NIH Research Portfolio Online Reporting Tools (RePORT). NIH RePORTER version 7.10.0. Available from: https://projectreporter.nih.gov/ reporter.cfm. Accessed January 5, 2015. 